\title{
Aplicación de la pena natural al cónyuge sobreviviente
}

\section{Application of the natural penalty to the surviving}

\author{
Ximena Alexandra Gálvez-Sigüenza \\ ximena.galvez@psg.ucacue.edu.ec \\ Universidad Católica de Cuenca, Cuenca \\ Ecuador \\ https://orcid.org/0000-0002-0697-6835 \\ Cecilia Ivonne Narváez-Zurita \\ inarvaez@ucacue.edu.ec \\ Universidad Católica de Cuenca, Cuenca \\ Ecuador \\ https://orcid.org/0000-0002-7437-9880 \\ Juan Carlos Erazo-Álvarez \\ jcerazo@ucacue.edu.ec \\ Universidad Católica de Cuenca, Cuenca \\ Ecuador \\ https://orcid.org/0000-0001-6480-2270 \\ Camilo Emanuel Pinos-Jaén \\ cpinosj@ucacue.edu.ec \\ Universidad Católica de Cuenca, Cuenca \\ Ecuador \\ https://orcid.org/0000-0002-0934-8471
}

Recibido: 10 de abril de 2020

Revisado: 30 de abril de 2020

Aprobado: 24 de mayo de 2020

Publicado: 14 de junio de 2020 


\title{
RESUMEN
}

Este artículo pretende determinar en qué medida atenta la falta de aplicación de principios de igualdad y proporcionalidad a favor del cónyuge sobreviviente o conviviente en un delito culposo de tránsito, al ser excluido de la redacción del artículo 372 del Código Orgánico Integral Penal, en base de análisis de casos, literatura legal y normas del ordenamiento jurídico. Para este propósito, se aplicó el método analítico-sintético con la investigación de fuentes doctrinarias como también el inductivo-deductivo que permitió el estudio de casos, obteniendo como resultado que es imperativo la reforma de ley por atentar derechos constitucionales de quien forma parte esencial de un núcleo familiar, originada de una relación contractual solemne y afianzada por un vínculo natural de afectividad, siendo inconcebible que el cónyuge reciba un trato diferenciado para ciertas obligaciones civiles, no así en el campo penal podría llevar al presunto infractor a la privación de libertad.

Descriptores: Derecho constitucional; cónyuge; igualdad de oportunidades; familia. (Palabras tomadas del Tesauro UNESCO).

\begin{abstract}
This investigation aims to determine to what extent the lack of application of principles of equality and proportionality in favor of the surviving spouse or cohabiting in a guilty crime of transit, by being excluded from the drafting of article 372 of the Comprehensive Organic Criminal Code, based on analysis of cases, legal literature and norms of the legal system. For this purpose, the analytical-synthetic method was applied with the analysis of doctrinal sources as well as the inductive-deductive one that can have the analysis of cases, obtaining as a result that the reform of the law is imperative for the constitutional rights of which it is part essential of a family nucleus born or not of a solemn contractual relationship originated by a natural bond of affectivity, being inconceivable that the spouse contacted a different treatment, for certain civil obligations not so in the criminal field could lead the alleged offender to the deprivation of freedom.
\end{abstract}

Descriptors: Constitutional right; married men; equal opportunity; family. (Words taken from the UNESCO Thesaurus). 
Ximena Alexandra Gálvez-Sigüenza; Cecilia Ivonne Narváez-Zurita; Juan Carlos Erazo-Álvarez; Camilo Emanuel Pinos-Jaén

\section{INTRODUCCIÓN}

El artículo 195 de la Constitución de la República del Ecuador, manda Fiscalía General del Estado tendrá la facultad de iniciar o no un proceso penal, ejercerá la acción pública basada en principios de oportunidad y mínima intervención penal así como también prescribe la importancia de adecuar formal y materialmente las leyes y demás normas jurídicas a los derechos previstos en la Constitución y tratados internacionales (Asamblea Nacional Constituyente, 2008).

A parir de la vigencia del Código Orgánico Integral Penal en el año 2014, en el artículo 372 establece que la pena natural se aplicará a los parientes desde el cuarto grado de consanguinidad y segundo de afinidad, dejando al margen este derecho a favor del cónyuge sobreviviente en un delito culposo de tránsito (Asamblea Nacional, 2014).

La presente investigación está dirigida a determinar que al excluirse al cónyuge sobreviviente se descuidan los derechos innatos del ser humano sin considerar que la pena natural está definida como el sufrimiento natural del individuo y que a pesar de su trascendencia no se le ha dado importancia en el Ecuador; determinar que los operadores de justicia tanto jueces como fiscales tienen una limitación al no aplicar principios constitucionales de igualdad y proporcionalidad, por lo que se hace necesario reformar la norma infra constitucional y evitar se sigan vulnerando estos derechos.

Surge, por tanto, la necesidad de comprender si la pena que se aplica como un castigo a una conducta contraria a la ley puede ser desmedida y desproporcionada cuando se trata de imponerla a personas que intervienen en un delito culposo de transito cuya condición es faltar al deber objetivo de cuidado que este tipo de sanciones deben ser aplicadas bajo una perspectiva distinta considerando situaciones de orden humano y sin omitir lo que determina el principio de oportunidad.

Por lo señalado, en la presente investigación se plantea el siguiente problema ¿Cómo incide en la vulneración de los principios de igualdad y proporcionalidad en el tratamiento de la pena natural establecida en el Código Orgánico Integral Penal en el juzgamiento del cónyuge sobreviviente?, por consiguiente, el objetivo de la investigación consiste en plantear la reforma del artículo 372 del Código Orgánico Integral Penal para que la 
aplicación de la pena natural incluya al cónyuge sobreviviente y se evite la vulneración de los principios constitucionales de igualdad y proporcionalidad.

\section{Referencial teórico}

\section{La pena natural y los principios de igualdad y proporcionalidad}

La investigación sobre la pena natural es una preocupación constante dentro del campo penal por su falta de aplicación a favor del cónyuge sobreviviente en un delito culposo de tránsito, sin embargo, un problema de ésta magnitud no ha recibido la atención debida por parte de las autoridades del país, la pena natural no ha sido analizada desde un enfoque constitucional aplicando principios de igualdad y proporcionalidad, indispensables al momento de imponer una sanción penal.

Es definida como el dolor humano, la aflicción que deviene de un acontecimiento de carácter culposo, sin embargo, en un procedimiento penal de tránsito es aplicada a favor de los parientes del procesado ignorando al cónyuge y el sufrimiento que padece en el momento que enfrenta un dolor natural por ser el supuesto autor de un delito de tránsito. Al respecto, (Kant, 1978) distingue dos penas: la poena forensis o la sanción del Estado y la poena naturalis como el sufrimiento natural. En este contexto, se concluye que la persona que afronta un acontecimiento culposo ya padece una sanción intrínseca del hecho, por tanto, la imposición de una sanción penal por parte del Estado ya se considera desmedida. El autor considera que al momento de aplicar una pena se lo debe realizar desde perspectiva humana, aquella vista desde un tormento interno de la persona, cuya característica es la afectación emocional del individuo.

Además, es necesario definir a la pena como aquella sanción punitiva con el fin de imponer un castigo a conductas delictivas. (Ferrajoli, s.f) afirma que en transcurso del tiempo se han presentado tres tipos de pena: las informales de naturaleza causal privadas de la intervención punitiva, las naturales que tienen relación con la pena y el delito y las convencionales ligadas al carácter de índole jurisdiccional. Con respecto a la pena informal, la participación en el delito es de manera espontánea, sin planeamiento donde predomina la casualidad, en la pena natural existe una ideación que la pena es acorde al 
crimen, mientras que, en la tercera existe una relación entre la pena y el tipo penal y gravedad del delito. Entonces, es importante la clasificación realizada en líneas anteriores lo que reafirma el tema de estudio, por cuanto debe existir una distinción y adecuar condiciones determinantes y particulares en el momento que los jueces penales imponga una sanción por un delito de naturaleza culposa e incluso dolosa, teniendo como resultado una aplicación correcta del derecho.

Es necesario comprender lo que establece la Constitución de la República del Ecuador en su artículo 11 número 4 cuando manda que ninguna norma puede restringir los derechos constitucionales (Asamblea Nacional Constituyente, 2008). Es decir, los principios de igualdad y proporcionalidad no pueden ser inobservados, la Constitución es la norma suprema que garantiza que los derechos de un país y de un pueblo en general sean respetados. Dicho de otro modo, la norma inferior, no puede de ninguna forma ignorar el contenido de la norma suprema.

La importancia de definir principios constitucionales de igualdad y proporcionalidad se da cuando han sido desconocidos por la falta de aplicación de la norma del artículo 372 del Código Orgánico Integral Penal a favor del cónyuge sobreviviente más aún cuando existe tratados internacionales de cumplimiento obligatorio de los cuales Ecuador ha sido suscriptor y no han sido considerados.

La Convención Americana de Derechos Humanos en su artículo 24 indica que todas las personas son iguales ante la ley (Conferencia Especializada Interamericana sobre Derechos Humanos, 1969), así también, la Declaración Americana de los Derechos y Deberes del Hombre en su artículo II se pronuncia con respecto a la igualdad de las personas ante la ley sin distinción alguna (IX Conferencia Internacional Americana, 1948). Estos instrumentos internacionales han sido suscritos por los Estados partes que se obligan a cumplir estrictamente con lo estipulado, lo que denota que en el campo internacional la igualdad de las personas tiene relevancia humana razón por la cual, se deberían respetar y en conjunto con la Constitución de la República alcanzar lo anhelado por la sociedad que es sentir seguridad jurídica y que sus derechos sean protegidos aplicando principios constitucionales. 
De lo mencionado, se observa que la Constitución de la República del Ecuador en el artículo 66 número 4 establece el derecho a la igualdad formal y material (Asamblea Nacional Constituyente, 2008). Esto quiere decir que las leyes que se dictan dentro del ordenamiento jurídico deben ser promulgadas sin hacer distinción de ningún tipo hacia el conglomerado social lo que se conoce como igualdad formal mientras que la igualdad material va dirigida a su aplicación en igualdad de condiciones velando la seguridad jurídica. Al respecto, (Pérez, 2007) indica que la igualdad reúne tres características: la condición de ser iguales, una relacional porque tiene que existir un nexo y la comparación de la igualdad que es esencial para calificarla. Se debe entender entonces que la igualdad es un todo, por nuestra calidad de seres humanos, por las relaciones de convivencia mutua, y las diferencias que puedan surgir son únicamente físicas más no innatas del ser humano.

Es importante resaltar que la Constitución Política de Colombia en su artículo 13 establece que todas las personas son iguales ante la ley, y gozarán de igual protección sin discriminación alguna, debiendo destacar que esa no discriminación se extiende al origen nacional o familiar (Asamblea Nacional Constituyente, 1991). En este país se considera el principio de igualdad de las personas, se desarrollan los derechos constitucionales, proscriben actos de discriminación con absoluta protección a la familia como eje primordial en el desarrollo de la sociedad.

Es similar, al principio de igualdad la relevancia de la proporcionalidad que en la Constitución de la República del Ecuador en su artículo 76 número 6 manda que debe existir imposición de sanciones acorde a las infracciones consumadas (Asamblea Nacional Constituyente, 2008). Es decir, evitar la aplicación desmedida del castigo estatal con respecto a los actos lesivos cometidos, por tanto, debe existir coherencia entre éstos dos conceptos para que la sanción sea impuesta de tal manera que las personas que se sometan a un juzgamiento penal vean garantizados sus derechos.

Tanto es así que se considera al principio de proporcionalidad como aquel derecho que no es absoluto sino que contiene limitaciones o como más se conoce el límite de los límites (Carbonell, 2007). El problema de la proporcionalidad es equiparar el peso entre 
la sanción y el acto ilícito de tal modo que no existan consecuencias severas y se respete los derechos de personas.

(Beccaria, 2015) refiere que el principio de proporcionalidad es aquel contraste de la sanción y la moderación, ninguna pena puede ser igual cuando se ofende de manera distinta a la sociedad, el fin es no afectar al autor de un hecho ni restaurar el cometido sino buscar un equilibrio entre el imputado delito y la sanción. La falta de proporcionalidad provocaría una desestabilización y la inseguridad jurídica a las personas sometidas a un proceso penal. De ahí que, deviene la responsabilidad de los operadores de justicia de analizar de manera objetiva e imparcial la imposición de una sanción de acuerdo con la gravedad del delito y que merece un reproche de la sociedad.

(Ferrajoli, s.f) define al principio de proporcionalidad como la relación que existe entre el hecho reprochable y la pena que a la vez debe ser concordante con lo realizado por la legislatura y aplicada por el juez. En este contexto, la proporcionalidad debe llevar el equilibrio implícito y no desproporcionado y esto parte desde el momento de la creación de la norma por parte del legislador y termina en la aplicación correcta por parte del juez en un proceso.

De igual manera, Bernal (como se cita en Mogrovejo-Gavilanez, Erazo-Alvarez , NarváezZurita, \& Pozo-Cabrera, 2019) define al principio de proporcionalidad como la armonía y el equilibrio del ser humano que no puede estar alejado de los valores del derecho y de justicia, por lo que es trascendental considerar la primacía del principio de proporcionalidad al fin de establecer un correcto contrapeso en la sociedad, más aún deben estar en armonía con los derechos y principios constitucionales, tratados internacionales y hasta de los llamados derechos innominados.

El omitir principios de igualdad y proporcionalidad por la falta de aplicación de la pena natural a favor del cónyuge sobreviviente trae como consecuencia la deshumanización del derecho penal que tiene como fin encontrar la verdad, porque el derecho penal tiene que ser humano, la pena no debe buscar crueldad sino la rehabilitación del individuo en la sociedad. 
Ximena Alexandra Gálvez-Sigüenza; Cecilia Ivonne Narváez-Zurita; Juan Carlos Erazo-Álvarez; Camilo Emanuel Pinos-Jaén

Es indudable que la pena natural tiene que ser vista desde un enfoque distinto, esto significa en aplicarla no sólo por la relación de parentesco desde el cuarto grado de consanguinidad y segundo de afinidad como establece la norma infra constitucional (Asamblea Nacional, 2014), sino que se debe enfocar su problemática desde una perspectiva constitucional considerando principios de igualdad y proporcionalidad.

\section{Tratamiento de la pena natural en la legislación ecuatoriana}

En el ordenamiento jurídico del Ecuador, es necesario que se incluya la pena natural basada en un principio de oportunidad, con la finalidad de que Fiscalía General del Estado inicie o no un proceso penal, considerando las repercusiones y consecuencias en la vida de la persona involucrada. La pena natural produce un sentimiento de soledad y sufrimiento, el dolor puede ser más severo si va acompañado de una presunta responsabilidad de naturaleza culposa. La pena natural se encuentra prescrita en el artículo 372 del Código Orgánico Integral Penal que establece:

En caso de pena natural probada, en las infracciones de tránsito y cuando la o las víctimas sean parientes del presunto infractor hasta el cuarto grado de consanguinidad o segundo de afinidad, la o el juzgador podrá dejar de imponer una pena o imponer exclusivamente penas no privativas de libertad. (Asamblea Nacional, 2014, art.372)

Partiendo del texto del referido artículo, es claro y demostrable que el cónyuge sobreviviente o conviviente que fuera presunto responsable en un evento de tránsito con muerte no podría beneficiarse de la pena natural, por cuanto la norma limita hasta el cuarto grado de consanguinidad y segundo de afinidad, lo que lleva a cuestionar la aplicabilidad de la norma al parentesco de afinidad o parentesco político desconociendo el contrato solemne de matrimonio, sus fines y su institución jurídica.

De acuerdo con lo expuesto en el párrafo anterior, la normativa del Código Civil en su artículo 81 establece que el matrimonio es la unión entre dos personas con fines familiares y de convivencia (Asamblea Nacional, 2015). En el ordenamiento jurídico ecuatoriano el cónyuge sobreviviente o al conviviente no tiene ningún tipo de relación de parentesco con respecto a su esposo. Los cónyuges no son parientes entre sí. (Claro- 
Ximena Alexandra Gálvez-Sigüenza; Cecilia Ivonne Narváez-Zurita; Juan Carlos Erazo-Álvarez; Camilo Emanuel Pinos-Jaén

Solar, 2013), señala que el matrimonio es la relación de familia que existe entre dos personas. La propia ley indica que el matrimonio es un contrato de naturaleza solemne, esta cualidad lleva implícita un tratamiento con consecuencias en el ámbito territorial y en el extraterritorial lo que conlleva derechos y obligaciones entre los contrayentes y su descendencia.

Por otra parte, corresponde anotar también que el propio Código Civil reconoce a la unión de hecho como aquella relación libre de un lazo legal con los mismos derechos y obligaciones que un matrimonio (Asamblea Nacional, 2015). En este sentido, el tratadista (Claro-Solar, 2013) la define como la relación carnal sin vinculo legal. Debiendo entenderse como una relación de dos personas que sin estar unidas a través de un contrato solemne mantienen vínculos de convivencia la misma que crea similares derechos y obligaciones que el matrimonio.

En la legislación ecuatoriana existen dos tipos de parentesco, por consanguinidad llamada también natural (Asamblea Nacional, 2015). Siendo, la relación que se origina de un mismo tronco familiar y unidos por el vínculo de sangre, lo que se denomina la familia y el parentesco por afinidad o conocido como la relación política. Es decir, aquella relación que crea la ley por el acto de matrimonio que si bien no existe parentesco si existe una relación de familiaridad por el nexo de la convivencia.

En el artículo 13 del Código Orgánico Integral Penal se establece que la interpretación en materia penal se hará en el sentido literal de la norma y con armonía a la Constitución y tratados internacionales (Asamblea Nacional, 2014). En base al artículo citado los operadores de justicia deberían aplicar la norma interpretándola con el fin de que se favorezcan los derechos del justiciado, sin embargo, esto no ocurre en los sucesos de tránsito con muerte en los que por su propia naturaleza son culposos y se excluye al cónyuge o conviviente que presuntamente hubiere infringido el deber objetivo de cuidado, lo que hace inaplicable la Constitución y tratados internacionales de derechos humanos en esta materia.

Para dar luz a las numerosas cuestiones que se presentan en el campo de estudio, el artículo 18 el Código Orgánico Integral Penal instituye a "la conducta típica, antijurídica y 
Ximena Alexandra Gálvez-Sigüenza; Cecilia Ivonne Narváez-Zurita; Juan Carlos Erazo-Álvarez; Camilo Emanuel Pinos-Jaén

culpable" (Asamblea Nacional, 2014, art.18). Se describe el contenido de la norma penal como las conductas que merecen un reproche penal, en tanto que, la antijuricidad es la conducta contraria al ordenamiento jurídico y la culpabilidad entendida como la responsabilidad en sus diferentes grados. El estudio de estas condiciones lo indican (Muñoz-Conde \& García-Arán, 2010) cuando determinan a la antijuricidad mediante el cometimiento de un hecho contrario a la ley y que será necesaria la culpabilidad para imponer una sanción penal.

En el estudio de la pena natural se requiere que la culpabilidad sea vista desde un punto de vista humano y natural al que pudiera estar avocado quien tiene la calidad de cónyuge y o conviviente. Así en el Código Orgánico Integral Penal en el artículo 27 determina a la culpa como la falta del deber objetivo de cuidado por parte del supuesto infractor en un delito de tránsito (Asamblea Nacional, 2014). En un delito de tránsito el presunto infractor descuida el actuar correcto y prudente lo que da un resultado la muerte que en la legislación ecuatoriana es castigada con la imposición de la pena del Estado. (Zaffaroni, 2006) cuando define el acto doloso como el dominio de hecho mientras que el culposo se falta al deber objetivo de cuidado; para el escritor, en la autoría dolosa existe el conocimiento y voluntad para causar daño mientras que en la autoría culposa se produce cuando el responsable no acata el deber objetivo de cuidado sin previsibilidad en su actuar pero causa un resultado lesivo.

La normativa jurídica penal prevé la aplicación del principio de oportunidad en el artículo 412 del Código Orgánico Integral Penal definiéndolo como aquella potestad que tiene Fiscalía General del Estado de iniciar o desistir de una investigación penal (Asamblea Nacional, 2014). Se faculta a Fiscalía como órgano persecutor a adoptar un mecanismo válido que puede ser aplicado en delitos que no causen conmoción social, en el caso de estudio el fallecimiento en un delito de tránsito son de naturaleza violenta accidental por cuanto no existe dolo.

En base a estas consideraciones y a pesar de que existe una herramienta jurídica de aplicación de oportunidad en la legislación ecuatoriana no se emplea a favor del cónyuge sobreviviente o el conviviente por cuanto el contenido del artículo 372 de COIP lo 
restringe, inclusive desconociendo facultades constitucionales de Fiscalía General del Estado previstas en el artículo 195 de la Constitución de la República del Ecuador en cuanto tendrá en sus manos la acción pública con respeto a los principios de oportunidad y mínima intervención penal (Asamblea Nacional Constituyente, 2008). Se demuestra que no sólo se vulneran principios de igualdad y proporcionalidad sino también se desconoce las facultades de Fiscalía General del Estado como entidad pública de investigación pre procesal y procesal penal.

La tabla 1 ilustra la comparación del principio de oportunidad de otros ordenamientos jurídicos que lleven a unificar criterios a fin de que puedan aportar resultados positivos en beneficio siempre de la sociedad.

\section{Tabla 1}

\section{Principio de Oportunidad aplicado en las diferentes legislaciones}

País Código Penal Cód. Procedimiento Penal

Colombia

Argentina

Perú

Alemania

$\mathrm{X}$

$X$

$X$

$x$
Artículo 324

31

2

60

Fuente: Códigos Penales Perú y Alemania y Códigos Procesales Penales Colombia y Argentina.

Los códigos penales y procesales penales de Colombia, Argentina, Perú y Alemania delimitan a los delitos culposos como aquellos que se revisten de un razonamiento de oportunidad, se considera el sufrimiento que enfrenta el procesado e incluso tienen la potestad de aplicar este principio en los delitos dolosos, todos ellos tienen como fin el evitar una aplicación desmedida de la pena estatal, la legislación comparada demuestra que no hay necesidad de una justicia inquisitiva, al contrario se tiene razonamientos basados en una justicia de derechos, situación que corrobora que en la pena natural no 
Ximena Alexandra Gálvez-Sigüenza; Cecilia Ivonne Narváez-Zurita; Juan Carlos Erazo-Álvarez; Camilo Emanuel Pinos-Jaén

sería necesaria la privación de la libertad del sujeto activo del delito.

\section{Pena natural: el ejercicio de los principios constitucionales}

Este artículo académico tiene como objetivo proporcionar una mejor base para la comprensión de los principios constitucionales de igualdad y proporcionalidad, en el ordenamiento jurídico existen varios cuerpos legales que no se adecúan con las normas constitucionales lo que origina la existencia de anomias y antinomias que se enfrentan con derechos consagrados en la Constitución y tratados internacionales siendo así el caso de la pena natural. (Gargarella, 2008) afirma:

La idea de tener una Constitución "viva" resulta, a primera vista al menos, muy atractiva, porque ella viene a descalificar una alternativa que parece claramente desagradable, cuál es la de estar "sujetos por la mano muerta del pasado". Quienes postulan a la "actualización" permanente de la Constitución nos prometen, entonces, una vida jurídica "moderna" acorde a los tiempos. (p.124)

Ante los cambios de la sociedad el poder legislativo debe procurar que sus decisiones se adecúen al contenido constitucional tal como se ha indicado en líneas anteriores, el tiempo evoluciona, por tanto, las leyes deben adaptarse con el fin de proporcionar a la sociedad la seguridad jurídica que requiere. La Constitución tiene como fin la adaptación de los cuerpos normativos acorde a los intereses y nuevos contextos sociales, políticos y económicos.

En este sentido, el artículo 424 de la Constitución establece la supremacía constitucional (Asamblea Nacional Constituyente, 2008); el artículo motivo de estudio no garantiza la aplicación de derechos y se contrapone de manera evidente con la Constitución de la República del Ecuador. La pena natural debe ser compatible con normas constitucionales y tratados internacionales a fin de garantizar derechos. Se debe aplicar un principio de oportunidad de acuerdo con las facultades de Fiscalía General del Estado y tal como se justifica con la normativa legal en base del derecho comparado.

Los administradores de justicia no pueden moverse más allá de lo que la norma prescribe, más aún en materia penal los tipos penales y las penas son de interpretación literal 
Ximena Alexandra Gálvez-Sigüenza; Cecilia Ivonne Narváez-Zurita; Juan Carlos Erazo-Álvarez; Camilo Emanuel Pinos-Jaén

(Asamblea Nacional, 2014). En tal sentido, el juez penal tiene una camisa de fuerza frente a la aplicación de la pena natural. Debe considerarse que a través de la reforma legislativa se materialice la garantía constitucional normativa que consiste en la armonía real entre el texto constitucional y la norma secundaria o infra constitucional.

Es indudable, la importancia que reviste el problema planteado en lo que respecta a la aplicación de la pena natural al cónyuge sobreviviente o al conviviente en materia de tránsito. Como tema de investigación; la finalidad es demostrar su importancia que debe ser valorada desde un inicio y antes de la imposición de la pena que incluso puede abocar a la privación de la libertad de la persona procesada pretendiendo que el encierro de una persona resarciría la muerte de otra. Se debe considerar desde su naturaleza misma corroborando que no guarda ninguna correspondencia con los principios constitucionales que estamos obligados a observar. En el Ecuador, más grave resulta la derogatoria del artículo 173 de La Ley Orgánica de Transporte Terrestre Tránsito y Seguridad Vial que establecía:

Que en aquellos delitos donde por las circunstancias, el infractor sufriere un daño físico y grave que le imposibilite llevar una vida normal o las únicas víctimas fuesen su cónyuge o pareja en unión libre y familiares comprendidos hasta el segundo grado de consanguinidad, a petición del Fiscal y luego de constatar que en el caso concreto la aplicación de la pena no responde a un interés social, el juez puede conceder el principio de oportunidad y archivar el caso previa audiencia (Asamblea Constituyente, 2008, art.173).

El artículo transcrito contemplaba al cónyuge o pareja en unión de hecho y a los familiares hasta el segundo grado de consanguinidad como beneficiario del principio de oportunidad dejando en manos de Fiscalía General del Estado la competencia de iniciar o no un proceso penal en base de sus atribuciones contempladas en el artículo 195 de la Constitución de la República del Ecuador.

Hasta su derogatoria el artículo 173 de la Ley Orgánica de Tránsito Transporte Terrestre y Seguridad Vial reconocía y protegía al cónyuge o al conviviente en un delito culposo de tránsito. Al entrar en vigencia el Código Orgánico Integral Penal, el principio de oportunidad y la pena natural dentro del cuerpo normativo se encuentran definidos por 
separado y con concepciones diferentes, se modifica la esencia misma del matrimonio, la unión de hecho, el parentesco y las facultades de Fiscalía General del Estado. La normativa ecuatoriana ha sufrido un sinnúmero de reformas, modificatorias y cambios, lo que lleva a preguntar si fueron adecuadas conforme la técnica jurídica que puede ser incluso considerada como una regresión de derechos alterando lo que ordena la Constitución de la República del Ecuador en su artículo 1 número 8 cuando de manera taxativa indica que los derechos se desarrollaran de manera progresiva (Asamblea Nacional Constituyente, 2008).

La Corte Nacional en su última resolución de fecha 4 de diciembre del 2019, se pronuncia ante la consulta planteada por la Jueza de la Sala de lo Penal de la Corte Provincial de Justicia de Pichincha en lo que refiere a la pena natural, la Corte excluye al cónyuge basando su decisión en los artículos 22 y 23 del Código Civil indicando que el matrimonio es un contrato, por tanto, la pena natural no alcanza al cónyuge o a la pareja en unión de hecho (Corte Nacional de Justicia, 2019).

Se demuestra una vez más que los Jueces de la Corte Nacional del Ecuador hacen un análisis de aplicación de la norma inferior contenida en el Código Civil al manifestar que el matrimonio es un contrato, dejando de lado el análisis de fondo que se debe hacer en el caso de la pena natural sin tomar como base para su resolución derechos constitucionales de aquellas personas que se encuentran inmersas en un delito culposo de tránsito, se aplica un derecho deshumanizado sin considerar la pena o el sufrimiento del infractor.

El poder legislativo violenta la prohibición de regresividad como elemento esencial de la progresividad, menoscabando los derechos de las personas. La progresividad implica que una vez alcanzado un nivel determinado de protección constitucional este derecho no debe ser trastocado de ningún modo, tanto es así que serán inconstitucionales acciones $u$ omisiones de las autoridades públicas y se prohíbe el menoscabo de los derechos (Asamblea Nacional Constituyente, 2008).

La regresividad no está permitida bajo ningún concepto, no se puede anular el ejercicio de los derechos, debe existir un respeto irrestricto de lo alcanzado, si se considera la 
regresividad de un derecho se deberá hacerlo de manera excepcional siendo sometida a un juicio muy riguroso en el debate de esta ley, en el caso del Ecuador la situación referida no ha sido cumplida.

Se prevé en el ordenamiento jurídico ecuatoriano el artículo 428 de la Constitución de la República del Ecuador que establece que ante cualquier señal de inconstitucionalidad de norma secundaria los operadores de justicia están facultados a realizar una consulta ante la Corte Constitucional quien hará su pronunciamiento en aplicación de la norma suprema y tratados internacionales de derechos humanos (Asamblea Nacional Constituyente, 2008). Además, Ávila-Santamaría (como se cita en Andrade-Torres, Erazo-Alvarez, Trelles-Vicuña, \& Narvàez-Zurita, 2019) manifiesta que la Corte Constitucional al ser el organismo de máxima interpretación constitucional realizará un control adecuado a fin de que las normas inferiores no vulneren derechos constitucionales. En consecuencia, se afirma lo manifestado en el presente artículo académico cuando se manifiesta que ninguna norma inferior podrá enfrentar la norma suprema y los tratados internacionales de derechos humanos.

\section{MÉTODO}

El presente estudio transversal fue de carácter descriptivo porque se analizó los principios de igualdad y proporcionalidad que se encuentran reconocidos en los tratados internacionales de derechos humanos así como también en la Constitución de la República del Ecuador y que han sido vulnerados por la norma infra constitucional del artículo 372 del Código Orgánico Integral Penal.

Para el análisis de los datos se utilizó un enfoque mixto, en la primera etapa se utilizó la técnica cualitativa con el análisis crítico de fuentes, recabando información y datos que han permitido realizar un examen de la aplicación indebida de la pena natural en el Ecuador; en una segunda etapa, con la aplicación de técnica cuantitativa y el uso de la estadística inferencial se procesaron los datos obtenidos a través de las encuestas realizadas a jueces de las unidades penales, agentes fiscales, docentes académicos y público en general así como la entrevista realizada a un juez de la sala especializada de 
lo penal del Azuay.

Los métodos que se emplearon en este artículo científico fueron: analítico-sintético porque permitió sobre la base de los estudios doctrinarios constitucionales se valoró las normas que son motivo de ésta problemática integrándolas entre las partes y el todo como un sistema de seguridad complejo. El método inductivo-deductivo, permitió la construcción de propuestas desde el análisis de casos particulares, estableciendo regularidades, generalizaciones y conclusiones que generaron aportes para solucionar la falta de aplicación en la norma inferior a favor del cónyuge sobreviviente.

La muestra del presente artículo se determinó a través de un muestreo por conveniencia, sustentado en la técnica no aleatoria y muestreo no probabilístico, los criterios establecidos fueron: la profesión de los encuestados, accesibilidad y tiempo. En consecuencia, la muestra estuvo conformada por 21 personas.

\section{RESULTADOS}

En esta fase de diagnóstico se contó con la participación de jueces penales, agentes fiscales, docentes universitarios y público que tuvo conocimiento de un accidente de tránsito. Desde este punto de vista, el estudio se orientó con el propósito de establecer la percepción que tienen los encuestados sobre la exclusión que se realiza al cónyuge sobreviviente en el artículo 372 del Código Orgánico Integral Penal, con lo que se demostró que impera la necesidad de reformar la norma inferior y evitar se vulneren derechos constitucionales.

La encuesta estuvo compuesta de dos unidades de análisis, con preguntas alternativas de respuestas preestablecidas, la primera unidad dirigida a jueces, fiscales y docentes universitarios conformada de 8 preguntas y la segunda aplicada al público en general constituida con 5 preguntas. La recopilación y análisis de la información obtenida es el sustento para la identificación del problema de estudio.

La primera unidad de análisis tuvo como objeto conocer si las personas encuestadas tienen información relacionada con el derecho penal y constitucional. Cuando se les preguntó, si se considera adecuada la aplicación del artículo 372 del Código Orgánico 
Integral Penal el 57.1\% respondió que no, (Ver figura 1) lo que confirma que el texto del artículo motivo de estudio no es el adecuado y que existe una falencia al no incluir al cónyuge sobreviviente en un delito culposo de tránsito, se demuestra que los jueces penales y agentes fiscales en su mayoría consideran que la aplicación de la norma infra constitucional es errónea.

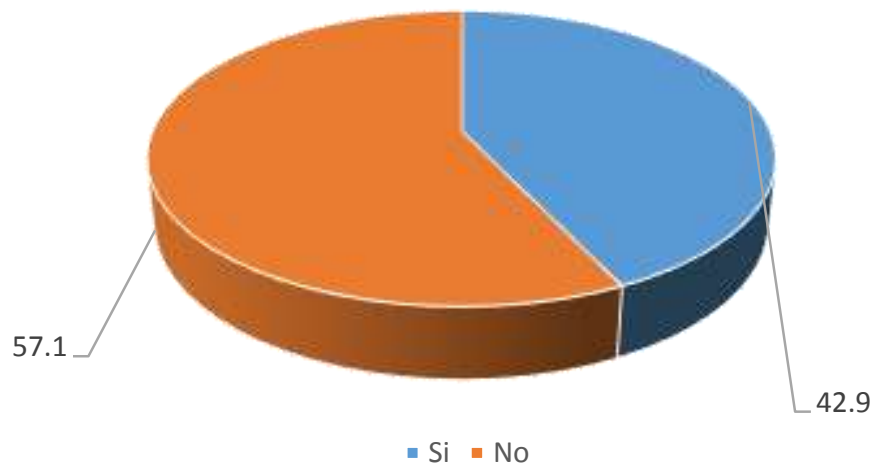

Figura 1. Aplicación del artículo 372 del Código Orgánico Integral Penal. Fuente. Jueces penales, agentes fiscales, docentes universitarios.

Como consecuencia a la pregunta anterior, los encuestados se pronuncian que el cónyuge sobreviviente en un delito culposo de tránsito debe ser incluido en el artículo 372 del Código Orgánico Integral Penal (Ver figura 2), obteniendo una respuesta del 91.7\% corroborando que los operadores de justicia tanto jueces penales, como garantistas de los derechos de las partes procesales, así como, agentes fiscales quienes tienen la titularidad de la acción penal pública están en total acuerdo que se incluya al cónyuge en la norma citada, mientras que un índice del apenas $7.10 \%$ se encuentra en desacuerdo a lo consultado. 


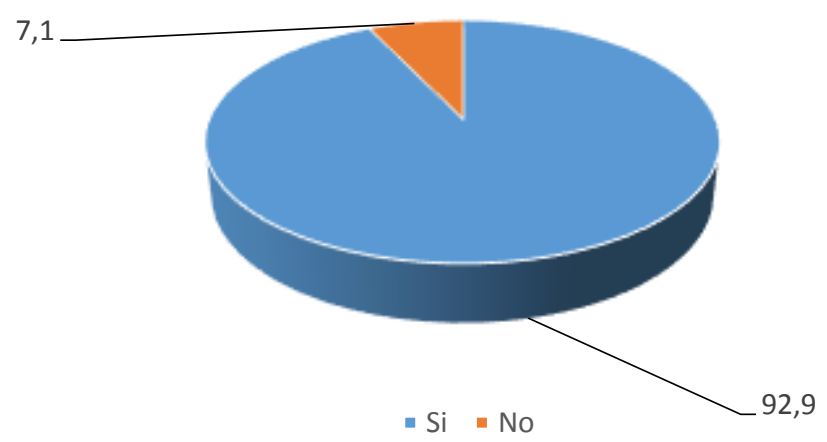

Figura 2. Inclusión del cónyuge sobreviviente en el artículo 372 del COIP. Fuente. Jueces penales, agentes fiscales y docentes universitarios.

El 92.9\% de los profesionales que fueron consultados se encuentran de acuerdo en que debe darse una reforma legislativa del artículo que motiva el presente estudio. (Ver figura 3), situación que reafirma que existe una redacción indebida de la norma inferior al considerar a los parientes desde el cuarto grado de consanguinidad y segundo de afinidad y no incluir al cónyuge sobreviviente como beneficiario de la pena natural, como consecuencia de esta posición, los consultados al responder la interrogante con criterio casi mayoritario de manera tácita piensan que el cónyuge sobreviviente es parte de un núcleo familiar y tendría los mismos derechos que los parientes políticos; y apenas un porcentaje mínimo del $7.10 \%$ no consideran la reforma. 


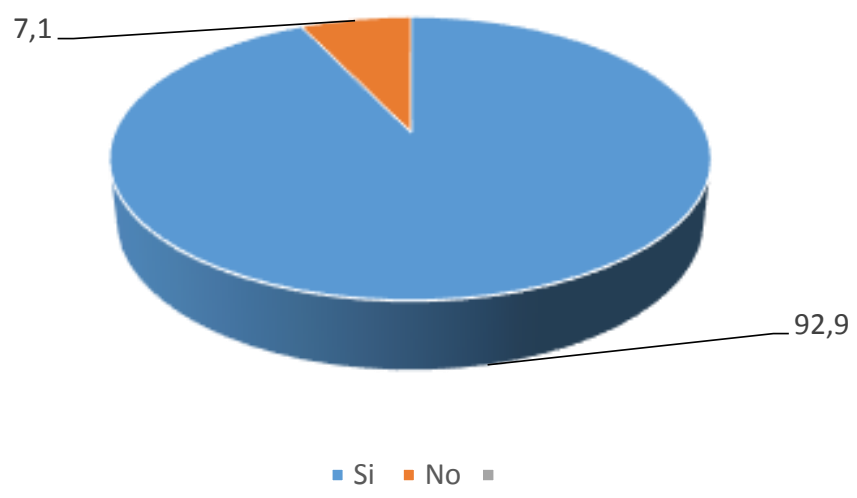

Figura 3. Reforma del artículo 372 del Código Orgánico Integral Penal. Fuente. Jueces penales, agentes fiscales, docentes universitarios.

Con los resultados obtenidos, en la presente encuesta se determina sin duda alguna que los operadores de justicia, es decir, jueces penales y agentes fiscales, así como también docentes universitarios concuerdan que el cónyuge sobreviviente al padecer un dolor natural, la imposición de una sanción estatal sería desmedida, tanto es así, que en la pregunta número siete, el 85.7\% (Ver figura 4) contestan que no debe existir una sanción penal al presunto responsable de un accidente de tránsito que tiene como resultado la muerte del cónyuge o conviviente, siendo un porcentaje del $14.3 \%$ que indica que si debe imponerse una sanción.

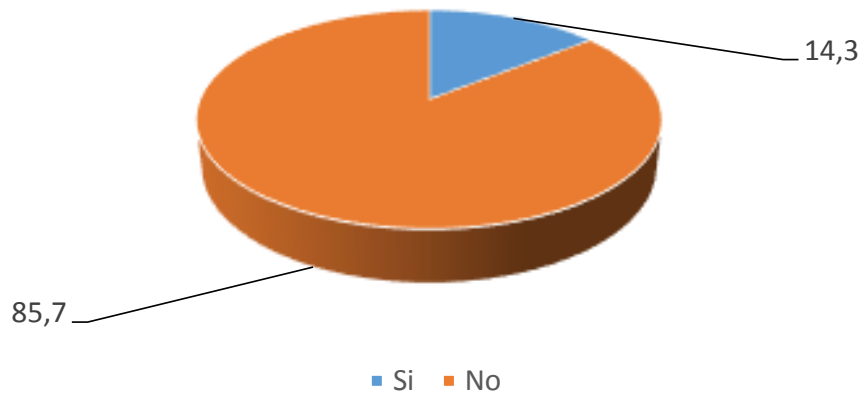

Figura 4. Reforma del artículo 372 del Código Orgánico Integral Penal. Fuente. Jueces penales, agentes fiscales, docentes universitarios. 
En la segunda unidad de análisis, se procedió a consultar a personas que dé una u otra forma han estado involucrados de manera directa o indirecta en sucesos de tránsito con resultados de muerte, dando como resultado que el $75 \%$ de encuestados, indican que el fallecido ha sido el cónyuge, mientras que el $25 \%$ corresponden a familiares consanguíneos y políticos; por lo que resulta lógico que el cónyuge o conviviente, debe ser beneficiado con la aplicación de la pena natural.

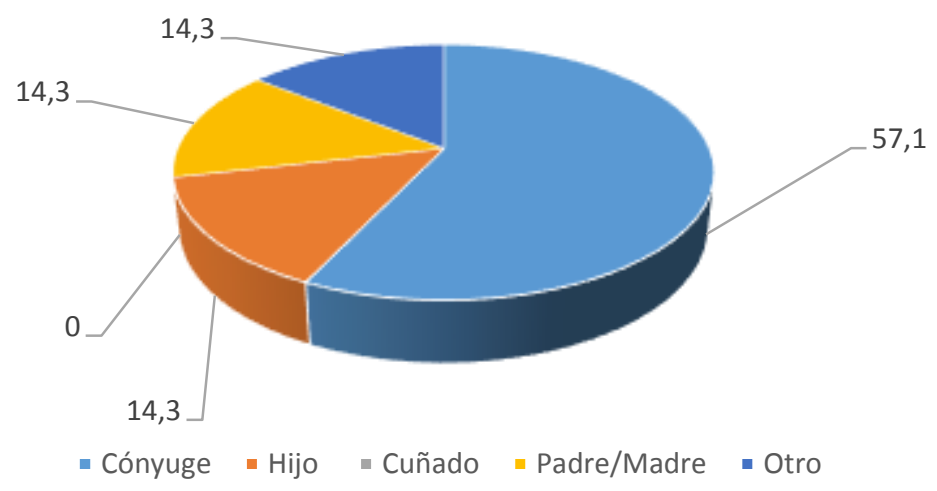

Figura 5. Reforma del artículo 372 del Código Orgánico Integral Penal. Fuente. Público en general

Por último, las personas encuestadas han referido en la pregunta cinco, en un 100\% que no están de acuerdo con ningún tipo de sanción penal para el cónyuge sobreviviente como presunto responsable en un accidente de tránsito, lo que determina que el Estado no debe ser un órgano de persecución penal descuidando al ser humano como un ente integrante de la sociedad, el derecho penal debe humanizarse en delitos de naturaleza culposa y las sanciones deben ser armónicas y equilibradas al hecho cometido, se debe sancionar basados en principios de igualdad y proporcionalidad incluyendo en el beneficio de la pena natural al cónyuge sobreviviente.

Los resultados obtenidos de las dos unidades de análisis concuerdan en la problemática del artículo 372 del Código Orgánico Integral Penal cuando se excluye al cónyuge sobreviviente como beneficiario de la pena natural, la redacción del artículo es deficiente y como consecuencia se vulnera derechos de igualdad y proporcionalidad. En 
consecuencia, es primordial la reforma de esta norma infra constitucional a fin de que no se vulneren derechos constitucionales.

\section{PROPUESTA}

A partir de los resultados obtenidos en el presente trabajo de investigación, se colige que es necesario adecuar a la normativa constitucional el artículo 372 del Código Orgánico Integral Penal mediante un proyecto de reforma de Ley.

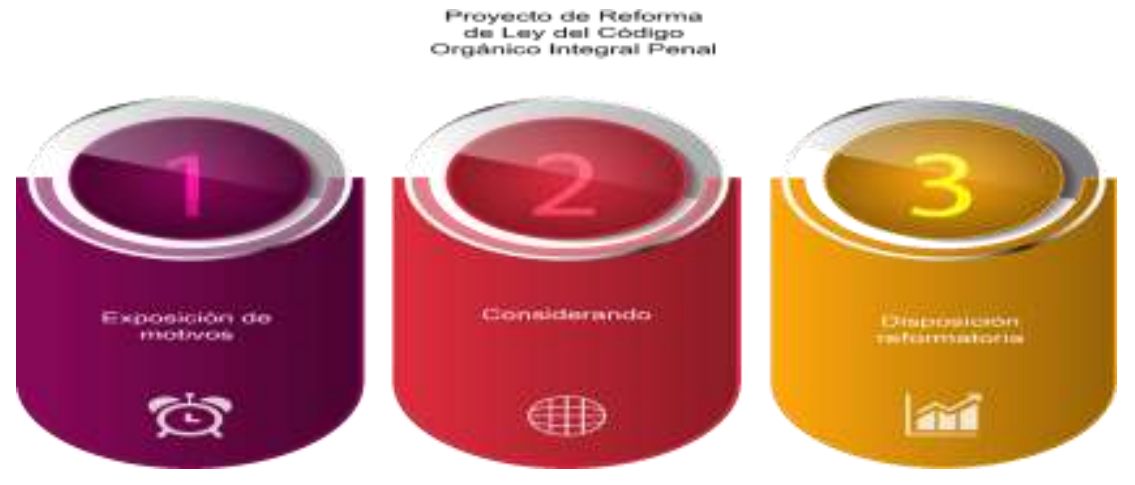

Figura 6. Esquema de propuesta de Reforma de Ley del Código Orgánico Integral Penal

\section{Proyecto de Reforma de Ley del Código Orgánico Integral Penal \\ Exposición de motivos}

El problema generado en el artículo 372 del Código Orgánico Integral Penal al no considerar al cónyuge sobreviviente como beneficiario de la pena natural, ha motivado proponer su reforma a fin de que se adecúe a los principios de igualdad y proporcionalidad reconocidos en la Constitución de la República del Ecuador así como también en los tratados internacionales de derechos humanos.

La pena natural establecida en la normativa penal, presenta un vacío legal al no incluir en el texto de la norma al cónyuge sobreviviente en un delito culposo de tránsito, excluyendo de un ámbito familiar a quien tiene un nexo legal que se origina por con un contrato de naturaleza solemne, dándose una importancia superior a los parientes hasta 
el cuarto de consanguinidad y segundo de afinidad, naciendo este último como consecuencia de este mismo contrato regulado en el Código Civil.

Al no existir un equilibrio entre la normativa infra constitucional y la Constitución de la República del Ecuador, se violentan los principios de igualdad y proporcionalidad que se debe observar de manera obligatoria en el momento de aplicar una sanción de tipo penal considerando que al no hacerlo se puede incurrir en la privación de libertad del presunto responsable en un suceso de tránsito. Por lo referido, se presenta la propuesta de reforma de Ley del Código Orgánico Integral Penal.

\section{Considerando}

Que el Art. 11 número 4 de la Constitución de la República del Ecuador establece que ninguna norma puede restringir los derechos constitucionales.

Que la Convención Americana de Derechos Humanos en su artículo 24 indica que todas las personas son iguales ante la ley.

Que la Declaración Americana de los Derechos y Deberes del Hombre en su artículo II se pronuncia con respecto a la igualdad de las personas ante la ley sin distinción alguna. Que el Art. 66 número 4 de la Constitución de la República del Ecuador establece el derecho a la igualdad formal y material.

Que el Art. 76 número 6 de la Constitución de la República del Ecuador manda que debe existir imposición de sanciones acorde a las infracciones consumadas.

Que el Art. 424 de la Constitución establece la supremacía constitucional.

Que el Art. 1 número 8 de la Constitución de la República del Ecuador de manera taxativa indica que los derechos se desarrollaran de manera progresiva.

Que el Art. 428 de la Constitución de la República del Ecuador establece que ante cualquier señal de inconstitucionalidad de norma secundaria los operadores de justicia están facultados a realizar una consulta ante la Corte Constitucional quien hará su pronunciamiento en aplicación de la norma suprema y tratados internacionales de derechos humanos.

Que el Art. 372 del Código Orgánico Integral Penal prescribe.- en caso de pena natural 
Ximena Alexandra Gálvez-Sigüenza; Cecilia Ivonne Narváez-Zurita; Juan Carlos Erazo-Álvarez; Camilo Emanuel Pinos-Jaén

probada, en las infracciones de tránsito y cuando la o las víctimas sean parientes del presunto infractor hasta el cuarto grado de consanguinidad o segundo de afinidad, la o el juzgador podrá dejar de imponer una pena o imponer penas no privativas de libertad En ejercicio de sus facultades constitucionales y legales, previstas en el numeral 6 del artículo 120 de la Constitución de la República del Ecuador, la Asamblea Nacional expide la siguiente:

\section{Proyecto de Reforma de Ley del Código Orgánico Integral Penal}

Artículo 1.- Añádase en el artículo 372 del Código Orgánico Integral Penal, a continuación de la frase "las víctimas", la frase "cónyuge sobreviviente o conviviente" Dado y suscrito, en la sede de la Asamblea Nacional ubicada en el Distrito Metropolitano de Quito, provincia de Pichincha, a los --- días del año 2020.

\section{DISCUSIÓN}

El artículo académico tuvo como objetivo plantear la aplicación de los principios de igualdad y proporcionalidad a favor del cónyuge sobreviviente en un delito culposo de tránsito y se evite la vulneración de principios constitucionales los que han sido reconocidos en la Constitución de la República del Ecuador y tratados internacionales de derechos humanos. En este contexto, se demostró que se debe aplicar una sanción penal a la persona que interviene en un suceso de tránsito desde una perspectiva humana, por tanto, la sanción del Estado en estos casos resultaría desproporcionada.

Fueron determinantes los resultados obtenidos en las encuestas realizadas a las dos unidades de análisis, los mismos que corroboraron que existe un problema en la redacción del artículo motivo de estudio y como consecuencia los operadores de justicia no pueden actuar más allá de lo que la norma penal permite, más aún cuando en esta materia la interpretación se hará en el sentido literal de la norma.

Es necesario dotar de herramientas jurídicas idóneas tanto a jueces como a fiscales a fin de que el limitante del artículo 372 del Código Orgánico Integral Penal desaparezca, se apliquen penas más humanas y se evite desde todo punto de vista la vindicta pública, 
para lo cual, se propone la reforma del artículo 372 del Código Orgánico Integral Penal para que la aplicación de la pena natural sea idónea y en armonía con el bloque de constitucionalidad y convencionalidad.

\section{FINANCIAMIENTO}

No monetario.

\section{AGRADECIMIENTO}

A las autoridades de la sala especializada de lo penal del Azuay.

\section{REFERENCIAS CONSULTADAS}

Andrade-Torres, J. A., Erazo-Alvarez, J. C., Trelles-Vicuña, D. F., \& Narvàez-Zurita, C. I. (13 de 12 de 2019). Conciliación en asuntos relacionados con infracciones de tránsito en el Ecuador Vulneración de derechos fundamentales. [Conciliation in matters related to traffic offenses in Ecuador Violation of fundamental rights]. Iustitia Socialis. doi:DOI: http://dx.doi.org/10.35381/racji.v5i8.566

Asamblea Constituyente. (7 de agosto de 2008). Ley Orgànica de transporte terrestre, trànsito y seguridad vial. [Organic Law of land transport, transit and road safety]. Del Control. Monteristi, Manabí, Ecuador: Registro Oficial No. 398.

Asamblea Nacional. (10 de febrero de 2014). Código Orgánico Integral Penal. [Organic Comprehensive Criminal Code]. Interpretación. Quito, Pichincha, Ecuador: Registro Oficial No. 180.

Asamblea Nacional. (19 de junio de 2015). Código Civil. [Civil Code]. Del Matrimonio. Quito, Pichincha, Ecuador: Registro Oficial No. 526.

Asamblea Nacional Constituyente. (20 de 07 de 1991). Constitución Política de Colombia. [Political Constitution of Colombia]. De los Derechos, las Garantías y los Deberes. Bogotá, Colombia: Gaceta Constitucional No. 116.

Asamblea Nacional Constituyente. (20 de octubre de 2008). Constitución de la República del Ecuador. [Constitution of the Republic of Ecuador]. Supremacía de la Constitución. Montecristi, Manabí, Ecuador: Registro Oficial No. 449. 
Ximena Alexandra Gálvez-Sigüenza; Cecilia Ivonne Narváez-Zurita; Juan Carlos Erazo-Álvarez; Camilo Emanuel Pinos-Jaén

Beccaria, C. (2015). Tratado de los delitos y de las penas. [Treaty of crimes and penalties]. Madrid: Committee.

Carbonell, M. (2007). El principio de proporcionalidad en el Estado constitucional. [The principle of proportionality in the constitutional state]. Bogotá: Proyectos Editoriales Curcio Penen.

Claro-Solar, L. (2013). Explicaciones de derecho civil chileno y comparado. [Explanations of Chilean and comparative civil law]. Chile: Editora e imprenta Maval Ltda.

Conferencia Especializada Interamericana sobre Derechos Humanos. (22 de noviembre de 1969). Convención Americana de Derechos Humanos Pacto de San José. [American Convention on Human Rights Pact of San José]. Deberes de los Estados y Derechos Protegidos. San José, Costa Rica: Registro Oficial No. 801.

Corte Nacional de Justicia. (4 de diciembre de 2019). Oficio Circular No. 20-2019-PCPJP. Resolución Corte Nacional de Justicia. Quito, Pichincha, Ecuador.

Ferrajoli, L. (s.f). Derecho y razón, Teoría del garantismo penal. [Law and reason, Theory of criminal guarantees]. Madrid: Trotta.

Gargarella, R. (2008). Teoría y Crítica del Derecho Constitucional. [Theory and Criticism of Constitutional Law]. Buenos Aires: Abeledo-Perrot.

IX Conferencia Internacional Americana. (1948). Declaración Americana de los Derechos y Deberes del Hombre. [American Declaration of the Rights and Duties of Man]. Capítulo Primero. Bogotá, Colombia.

Kant, I. (1978). Principios metafísicos de la doctrina del derecho. [Metaphysical principles of the doctrine of law]. México: Espuela de Plata.

Mogrovejo-Gavilanez, A., Erazo-Alvarez , J., Narváez-Zurita, C., \& Pozo-Cabrera, E. (17 de noviembre de 2019). Aplicación del Principio de proporcionalidad en la Jurisprudencia de la Corte Constitucional del Ecuador. [ Application of the Principle of proportionality in the Jurisprudence of the Constitutional Court of Ecuador]. Iustitia Socialis. doi: http://dx.doi.org/10.35381/racji.v5i8.563

Muñoz-Conde, F., \& García-Arán, M. (2010). Derecho Penal, Parte General. Valencia: Tirant lo Blanch.

Pérez, A. E. (2007). Dimensiones de la lgualdad. Madrid: DYKINSON, S.L. 
Iustitia Socialis. Revista Arbitrada de Ciencias Jurídicas.

Año V. Vol. V. ํ⒉ Edición Especial. 2020-II

Hecho el depósito de Ley: FA2016000064

ISSN: 2542-3371

FUNDACIÓN KOINONIA (F.K). Santa Ana de Coro, Venezuela

Ximena Alexandra Gálvez-Sigüenza; Cecilia Ivonne Narváez-Zurita; Juan Carlos Erazo-Álvarez; Camilo Emanuel Pinos-Jaén

Resoluciòn Corte Nacional de Justicia.[Resolution of the National Court of Justice] (4 de Diciembre de 2019).

Senado de la República de Colombia. (24 de 07 de 2000). Código Penal Colombiano. [Colombian Penal Code]. Bogotá, Colombia: Diario Oficial No. 44.097.

Zaffaroni, E. R. (2006). Manual de Derecho Penal, Parte General. [Criminal Law Manual, General Part]. Buenos Aires: Ediar.

(C2020 por los autores. Este artículo es de acceso abierto y distribuido según los términos y condiciones de la licencia Creative Commons Atribución-NoComercial-Compartirlgual 4.0 Internacional (CC BY-NC-SA 4.0) (https://creativecommons.org/licenses/by-nc-sa/4.0/). 